\title{
Exploring the Influence of Western Culture on Chinese Culture
}

\section{Fengyun Nie}

\author{
Weinan Normal University, Weinan, Shaanxi, 714000
}

Keywords: Western culture, Chinese culture, differences, collisions and conflicts, influence

\begin{abstract}
Chinese culture pays more attention to the self-cultivation and self-cultivation of the perceptual people, and the interaction with nature and nature, while the western culture is more focused on the maximization of the rational aspects of efficiency. Therefore, in terms of the measurement of Western culture, of course, Western culture is Chinese culture is superior to Chinese culture because it is more efficient than Chinese culture. Likewise, in terms of Chinese culture, Chinese culture is far advanced in Western culture because it is more harmonious than Western culture. With the development of economy and the world The controversy has not stopped yet, but more emphasis is placed on the influence of the cultures of China and the West on each other. Culture itself is a process of crudeness and refinement. This paper mainly discusses the conflicts between Chinese and Western cultures, The impact of Chinese culture.
\end{abstract}

China, as the birthplace of oriental culture, has the beauty of classical elegance. If the Chinese culture has the subtle and meticulous women, then the Western culture is the bold and straightforward man, Westerners ugly behavior in the brutal hegemony, and China is a rogue. Compared with the West, there are many common and obvious differences. Chinese people (referring to the ancients) have heavy feelings, Westerners, Chinese people, and Westerners. Although there are gentlemen in China who define themselves as altruistic and villain Yu Yuli, there is no conflict between love and reason, but China has always been less rational and often confuses the two. Fair in the world, often relying on notorious lawyers. In contrast, China is less rational and subjective. Westerners respect the objective facts and respect the rights of others. Fundamentally, it is for a stable order to protect their private property. Westerners are generally popular education, and their culture is more biased toward the creation of civilians. Most of the Chinese are due to official officials and doctors who are referred to school. The foreign leader as a whole has always been the king, and China is the emperor. As far as democracy is concerned, the Chinese people can make a mess. Foreign civilians culture fully embodies the idea of the civilian class. The broad masses of lower civilians generally do not have any special rights. They just want protection, equality, and human rights. They must work hard to run around for their own lives. The desire of the lower classes for the material is urgent. And because they can not rely on the privilege of the upper class is not too much, so they know better by their own strength. Westerners worship God, that natural human rights. Asia has always been divine right divine, all over the world, is not the king of soil; rate of the coast, Could Wang Chen. Authoritarian rule has deprived civilians of their private property and their rights. For a long time, the obscurantist people dominated the lower classes as slaves. They gave the minority intellectuals many privileges and used them only to control civilians and sing praises. The illiterate underclass culture is not reflected and disseminated, but the carefree taxons and physicians have created the aesthetic spiritual world, they are materialistic and often have many privileges, so that they study something closer to the soul Things that are closer to what humans perceive. As for the lower masses, they have only the spirit of impoverishment, so the same thing created by the scholar-officials paralyzes themselves and hopes for life.

Since modern times, we must promote mass education. This is the inevitable result of human civilization. We have eliminated class oppression and everyone is equal. The theme of Chinese culture must also be transferred to the vast majority of civilians. Pay more attention to material and economic development. The influence of thousands of years of traditional Chinese culture is 
profound. All people are anxious for freedom after turning over. However, they often desire to become the ruling class for thousands of years. The Chinese people will not look squarely at themselves and others. In the art of painting and sculpture, Westerners' philosophy of perspective and precision of anatomy are unattainable by Chinese people. In China, they often pay attention to the similarities and differences between one painting and the other. You often can not see what angle you are painting. More or less, Chinese people will not face up to others. For many thousands of years, the most revered hermits are self-righteous and typical opponents. China is unequal. Therefore, everyone is mentally at the highest point of the balance. Do not want to unequal competition, in fact, more unfair than them, there are many. To avoid bad, dying Freedom Freedom Scottish absolutely not allow themselves not to strive for the only right to survive the premature exit. For the punishments of criminals, the West often punishes the material and property. However, most Chinese people devastate their spiritual and physical lives. People's appraisal officials also tend to be honest and clean, and their performance is poorly discussed. Westerners call the aristocrats the upper class, and the class boundaries of the West are mainly measured by materiality. Even the title can be traded in the open because the title is inherently privileged and embodies the class ambiguity. The Chinese also completely formed a brand of mentality. In any case, maintaining an aristocratic attitude is no longer a bad thing. For thousands of years, the literati culture has been passed on to the ambitions of our homeland. Everyone lives as a savior, hoping that in reality we will do better. Now that the system in China has changed, we will be able to eliminate the dross in the tradition more easily from the traditional and the modern ones. We are convinced that we will safeguard each individual's human rights and respect our objective in an atmosphere of equality and freedom. Traditional culture has brought our spirit to the limit. Spirit is the closest thing to happiness and beauty. That kind of oriental flavor, is simply the most beautiful, beautiful flowers. Swallow Yan touch, Young Ying busy, bride paste new window, green thick flowers Courty Fang, good poem singing.

Chinese culture is like a shy and wayward beauty, like a proud ladylike, some rude and ignorant, of course, this is not cute at any time, her subjectivity sometimes brought a deep disaster to the people. Westerners, on the other hand, are smaller citizens who spend more time talking about their interests and laws.

Culture itself contains a measure of its own recognition. For example, Chinese culture, the more emphasis on perceptual self-cultivation and self-cultivation and nature and harmonious interaction; and Western culture, but more emphasis on the maximization of the rational aspects of efficiency. Therefore, in terms of the measurement of Western culture, western culture is certainly superior to Chinese culture because it is more efficient than Chinese culture. Likewise, in terms of Chinese culture, Chinese culture is far advanced in Western culture, because it is more harmonious than Western culture. As we have seen, people who hold the "advanced theory of Western culture" are strongly argued that the material civilization in the West is greatly developed and that their opposition insists that Chinese culture is "virtuous" Aspect occupies the highest point.

However, the economic basis is the decision of the superstructure, the superstructure counteraction and the economic base. With the rapid development of modern computer technology and the continuous development of the information revolution, China has successfully joined the WTO as one of them. Its ability to attract and accommodate the Chinese market has enabled more capital and culture Influx and jointly develop a more powerful and more dynamic market, Western capital in recent years have also been aimed at the Chinese market, a series of great moves, the corresponding will also bring cultural blend and collision, so that people do not unconscionably accept the western part of the culture worth learning, to achieve a strong culture of inclusive capacity and creativity.

The early McDonald's, KFC, and Starbucks entered the Chinese market. The steaming Chinese who adapted to the Chinese meal gradually accepted the so-called "Western Fast Food" in their passage of time and were willing to pay for it. Western fast food Most are burgers, bread, milk, coffee and other things that can quickly replenish energy and improve efficiency. Different from the slow fire of Chinese food, under the tide of economic tide, everyone is constantly being entrenched 
to move forward. Have to go to the pursuit of efficient, high quality of life, the speed of capital creation is staggering, in such a torrent, no one can stay out of the incident, so most people accept and love the convenience brought by foreign fast food and fast. It can be said that the influence of Western culture on Chinese culture has gained a sense of identity in the minds of Chinese people.

Westerners pursue the unity of time and pursue the current work efficiently and with high quality within a certain period of time. As mentioned above, in some ways, the western person behaved in some ways more like a small citizen who would like to pay the barbarians a day, Interests and laws. Especially in terms of time, the one-dimensional nature of time in Marxist philosophy expresses its emphasis on time as being different from that of its own people. It disgusts and repels all waste of time and censures the phrase "love you as time is life." The Chinese are lazy and casual in this respect. They are more diverse in time. They can deal with many things at the same time and can be interrupted and interrupted by various unexpected situations. In recent years, with the coming of western culture and the going of Chinese culture, more and more Chinese people began to study the scientificity and rationality of time distribution. "Tomato Law", "Time Management Law" and "Time to Be a Friend", various kinds of books continue to come out and are much loved and sought after by the Chinese people. To a certain extent, they cater to people's frustration over the current situation. In this respect, The Chinese are constantly learning the efficiency and punctuality of the West and have to say that this is a huge progress in the current international environment.

As we all know, November 20, 2017, Victoria's secret underwear show held in Shanghai, China, China has six models on the stage, to show the world the beauty of China. Some people say that this is a manifestation of the western capital market's downward bias toward a strong Chinese market. In fact, this means that China has a strong national strength and cultural soft power. When the force is sufficient to cooperate and compete with its rivals, the best result is that both parties to the competition Win-win.

December 7, 2017, Disney announced that with Liu Yifei to work together to create a "Mulan" movie, which is also out of Asia, the Chinese culture to the world an important manifestation of that year, excellent, such as Zhang Ziyi, Gong Li and other top Chinese women Actor, the best resource received in Hollywood is nothing but "Memoirs of a Geisha", and "Mulan" is a complete actress, Liu Yifei smooth play and superb English accent will undoubtedly be Western fans bring a visual and auditory feast, behind this incident, represents the impact of Western culture on Chinese culture, but also represents the Chinese culture going out and collision with the Western culture, and ultimately produce a better spark. All this is based on the strong national power and the increased cultural soft power.

To sum up, in order to achieve equal and face-to-face exchanges and dialogues over the past few years between Western culture and Chinese cultural exchanges, it is necessary to have strong national strength and cultural soft power as the basis and backing to achieve the ever-leaping economic situation Under the cooperation and win-win situation between China and the West. In this process, regardless of what kind of culture is better and which is worse, the culture of both China and the West is saturated with the cultural environment of a specific historical period, historical background and elements of the times, representing China The wisdom of the people and the Western people in real life. In today's situation, both Chinese and Western cultures are coming in and going out. They are also a rare bright color in the world's large gardens.

\section{References}

[1] On the relationship between Chinese and Western time viewpoints and the cultivation of intercultural communicative competence in Chinese international teaching, Ren Le - "Jiannan Literature: Classics Reading" - 2013 - Cited by: 1. Source: Wanfang / Love academic

[2] Analysis of the Intercultural Communication Barrier of the Movie "The 13 Girls of Jinling" Taking Cultural Conflicts Prominent in the Case of the "13 Days of Jinling" Seen by Western Media as an Example. Ke Wei - "Film Review" - 2012 - 3, 111-112.

[3] An Analysis of Collectivism's Impact on Cross-sectoral Collaboration - Based on a Comparative 
Perspective of Chinese and Western Cultures, Jiang Minjuan - Social Science in Yunnan 2016-02-01, 101-102.

[4] Transcending, Freeing and Surpassing between East and West - Reading New Perspective of Prof. Long Denggao, "Barriers to Crossing the Market: Overseas Chinese Entrepreneurs in the Country, System and Culture" Succeed, Starry Sky - "Historical Studies of Overseas Chinese" $2007-1$

[5] On the cultural differences between China and the West on the impact of intercultural communication, Wu Qing, Li Xiaohong, Zhejiang Institute of Media "Questions and Research: New Curriculum Forum" 2016 12, 123-124. 